\title{
Sea Salt Aerosols: Shortwave Radiative Forcing
}

\author{
Winai Meesang, Surat Bualert, and Pantipa Wonglakorn
}

\begin{abstract}
Effect of sea salt aerosol on short wave spectrum energy is the study of solar reduction and the reduction percentage due to sea salt aerosol. The research measured short wave radiation from the sun by using spectroradiometer, model MS700. The spectroraiometers were installed at two levels: the first level was set at $\mathbf{1 0}$ meters height from ground that called "control unit" representing the rays of the sun directly (direct Incoming) and the second level was set at one meter height that called "blank unit" measuring radiation from the sun passed through the blank chamber (Representing a decrease in solar radiation on Chamber / blank) and "laboratory unit" was a chamber with dry sea salt aerosol (Representing a decrease of the radiation from the sun and dried sea salt), then the study would find the percent reduction of solar radiation. The results show that the concentration of sea salt aerosol from $0.48,0.85$, 1.22, 1.59, $1.96 \mathrm{~g} / \mathrm{m}^{3}$. Aerosol particles caused the solar radiation reducing rate higher than sea salt aerosol at wavelength 306- $330 \mathrm{~nm}$ due to high energy (short wavelength) In addition.wave-length $380-390 \mathrm{~nm}$ increase solar radiation $f$ due to the properties of sea salt crystals $570-590 \mathrm{~nm}$ and $710-750 \mathrm{~nm}$ showed rapidly reduce energy.
\end{abstract}

Index Terms-Sea salt aerosol, solar spectrum shortwave, Thailand.

\section{INTRODUCTION}

Aerosol from the seawater it is particles of salt in (Sea Salt aerosol) is caused by the foam of the sea surface is dusty, rough (coarse aerosol) foam may be caused by biological, chemical or the influence of the wind. If the wind speed is greater than $3 \mathrm{~m} / \mathrm{s} 2$, it will shake the wave splashes and bubbles up. The bubbles of this size from 2-3 microns to 1000 microns bubble to the surface as a thin film.

The water is then broken up into small droplets produced when the wind blows into the atmosphere. Water will evaporate and the dust in the atmosphere ranging in size from 0.25 to 2.00 microns. other than Particles in accumulation and coarse modes with diameters from 0.08 to $3 \mathrm{~mm}$ scatter visible light most efficiently (Andreae, 1995; Quinn et al., 1996; Murphyet al., 1998b)Sea salt aerosol is produced by winds over the oceans (Mulcahy et al. 2008). Parameterizations based on the wind production relationship estimate an annual global total emission of 1,000-10,000 trillion grams $(\mathrm{Tg})$ of sea salt aerosol into the troposphere (Blanchard 1985). Sea salt particles are highly hygroscopic and easily grow to larger size (Irshad et al. 2009), leading to short residence time in the atmosphere. The suspended small sea salt particles are efficient in scattering solar energy, contributing largely to the marine aerosol optical depth

Manuscript received November 11, 2012; revised January 29, 2013.

The authors are with the Environmental Science Department, Faculty of Science, Kasetsart University. 50 Namwongvan Rd, Chatuchak Bangkok 10900, Thailand (e-mail: winai meesang@hotmail.com, surat.b@ku.ac.th).
(AOD) (Haywood et al. 1999). Sea salt aerosols play a dual role in affecting the atmospheric radiative balance. Directly, sea salt particles interact with the incoming solar radiation and the outgoing terrestrial radiation. Unlike the more hydrophobic soil dust aerosol, sea salt particles uptake water readily and, hence, are highly scattered at shortwave $(\mathrm{SW}$; solar) wavelengths with virtually no absorption (e.g., Takemura et al. 2002). Sea salt aerosol is not absorptive of solar radiation; it causes similar direct radiative perturbations at the surface and at the top of the atmosphere (TOA). In addition, sea salt aerosol can influence the formation and lifetime of clouds by acting as cloud condensation nuclei (Kaufman et al. 2005), leading to indirect changes in the Earth's energy budget.

The purpose of this study is the study of the reduction of the radiation from the sun, and the percentage reduction of the concentration of, sea salt aerosol.

\section{MATERIAL AND METHOD}

\section{A. Study Area}

The experiment was conducted at the experimental site of The King's Royally Initiated LeamPhakBia Environmental Research and Developmental Project (the Royal LERD-project) at Phetchaburi Province, Thailand

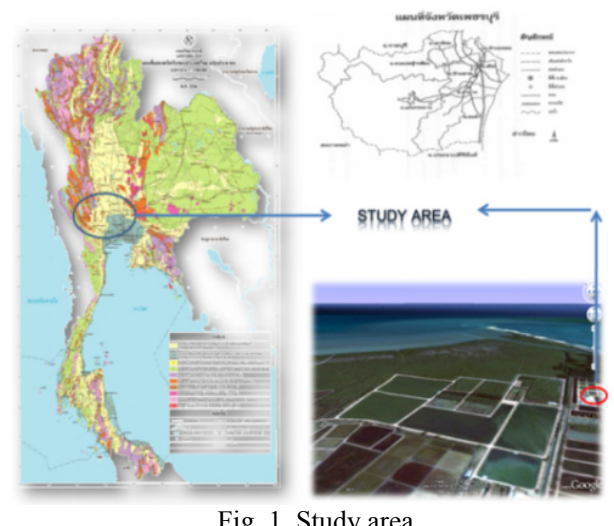

Fig. 1. Study area

\section{B. Field Experimental}

Field experiment was set up on September 2012.The measurement method used three unit of spectroradiometers (MS700) measuring and comparing the visible light energy in the difference conditions. The measurement period was between $11 \mathrm{am}-14 \mathrm{am}$. The experiment of three units shows that:

1) Control Unit measures the incoming solar radiation by tool "MS-700" at a height of 10 meters. The spectroradiometer, "MS700", would be used for measuring energy of the sun radiation at the continuous wave length or 
short wave spectrum (380-750 nm).

2) Blank Unit measures the effect of Trial Chamber. It made from acrylic at the packing cube shaped particle size $300 \times 300 \times 300 \mathrm{~mm}$. Under the chamber, MS-700, was installed to measure the energy of solar radiation passed through the blank chamber.

3) Laboratory Unit measures the effect of sea salt inside the Trial Chamber. The chamber was filled with sea salt aerosol at difference concentrations. The initial concentration of $0.48,0.85,1.22,1.59,1.96$ and $2.33 \mathrm{~g} / \mathrm{m}^{3}$. MS-700 was installed to measure the energy of solar radiation which pass through the chamber contained sea salt aerosol.

The experiments conducted by three MS-700 Spectroradiometers, which measure at the same time between 11:00 to 14:00 am (As show in Fig. 2).

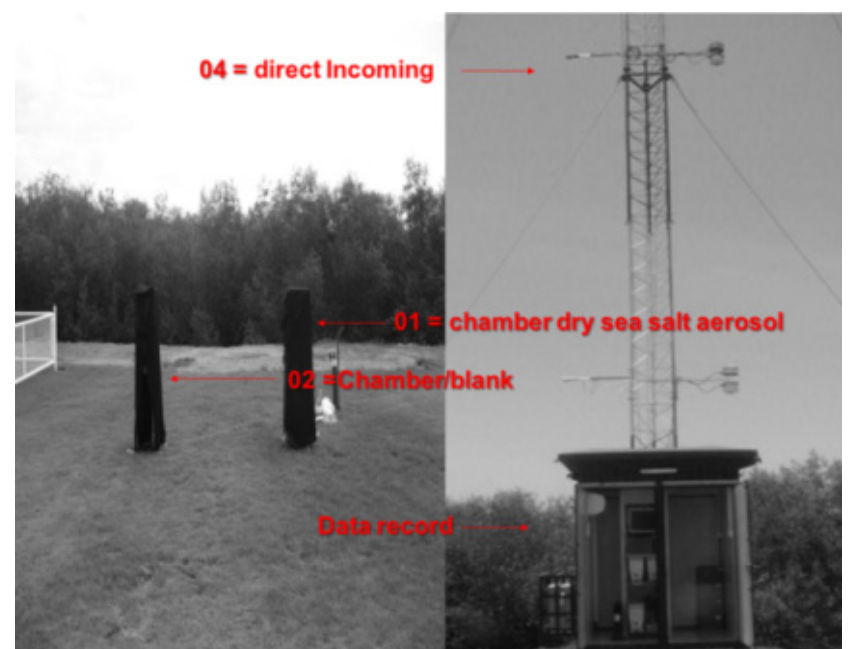

Fig. 2. Experimental Design

The effect of sea salt aerosol on the short-wave solar radiation defined as the difference of the incoming solar energy, the loosing energy caused by the sea salt and the chamber (as show in equation 1 ). The incoming solar energy was measured by the control unit. The energy that was loosed by chamber and sea salt aerosol was measured by blank unit and lab unit respectively.

$$
=\left(\begin{array}{c}
\text { Effect of sea salt aerosol } \\
\text { Control }- \text { Blank })-(\text { Control-Lab })
\end{array}\right.
$$

\section{RESULT}

Measurements in the energy range of the radiation detector, the MS-700 Spectroradiometer would check every $1 \mathrm{~nm}$ light from 350-1050 nm wavelength continuously for 24 hours, which was conducted on 18 September 2012 as the trial every 3 minutes including water heaters measurements. And the results is.

\section{A. Incoming Short-Wave Energy}

The averaged energies of spectral colors were 658.70 1090.571112 .06121 .311111 .391080 .44 and $937.55 \mathrm{~W} / \mathrm{m}^{2}$, respectively (as show in Figure 3) Compared with the measurement between 17 May 2011 to 21 March 2012 solar radiation monitoring Station at the King's Royally Initiated
LeamPhakBia Environmental Research and Developmental The maximum amount of solar radiation $1167 \mathrm{~W} / \mathrm{m}^{2}$ ) (as show in Fig. 3).

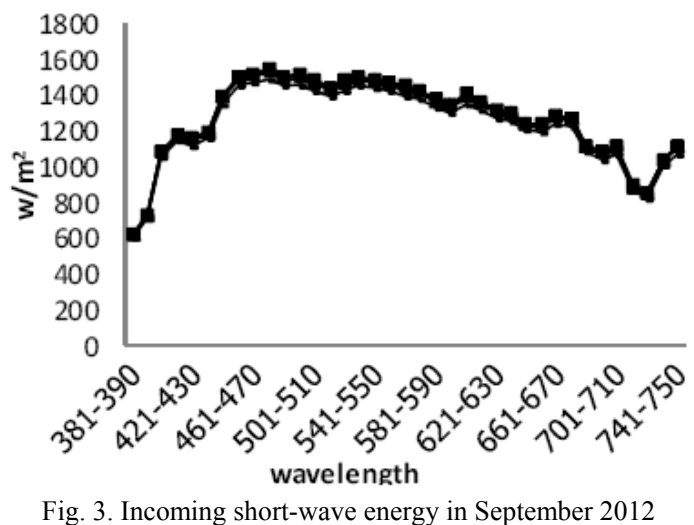

\section{B. Effects of Blank Chamber on Shortwave Energy}

The averaged energy passed through the blank chamber was decreased $318.19 \mathrm{~W} / \mathrm{m}^{2}$. The averaged energies of spectral colors were decreased 357.55, 388.51, 371.71, $332.60,285.85,286.06$ and $205.04 \mathrm{~W} / \mathrm{m} 2$, or $34.34,25.74$., $24.67,22.72,20.58,21.05$ and 18.11 percent respectively, (as show in Fig. 4).

\section{Effects of Sea Salt and Chamber on Shortwave Energy}

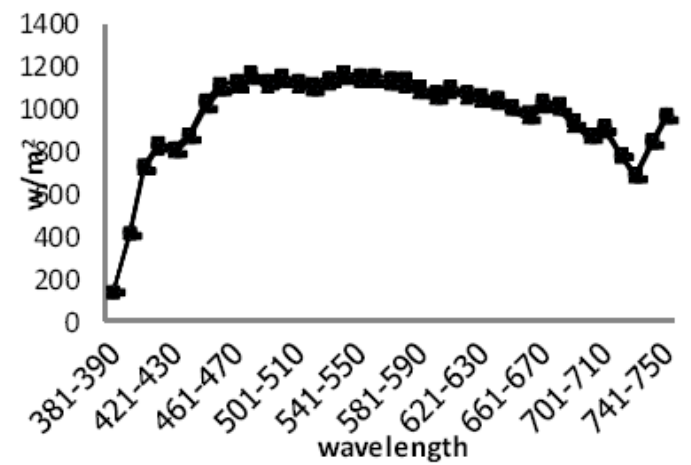

Fig. 4. Decreasing energy due to blank chamber in September 2012

Sea salt energy passed through chamber contained soil particle was decreased $327.06 \mathrm{~W} / \mathrm{m}^{2}$ The averaged energies of spectral colors were decreased 463.86, 551.68, 529.91, $477.09,406.83,405.07$ and $298.39 \mathrm{~W} / \mathrm{m} 2$, or $36.74,27.74$, $26.20,23.41,19.96,20.49$ and 17.18 percent, respectively (as show in Fig. 5)

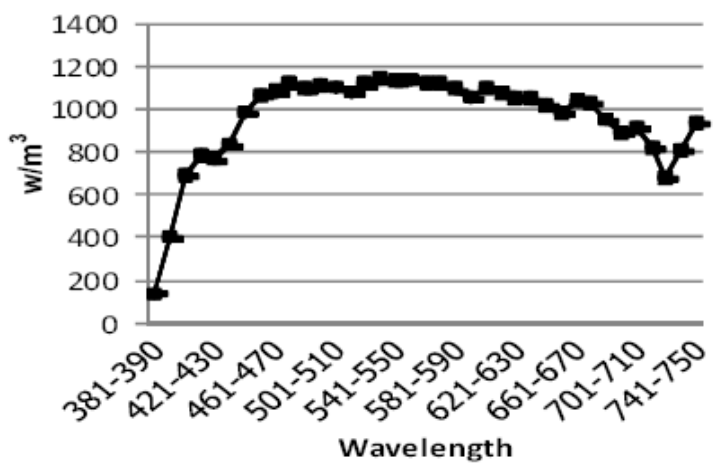

Fig. 5. Decreasing energy due to chamber contained sea salt aerosol in September 2012. 


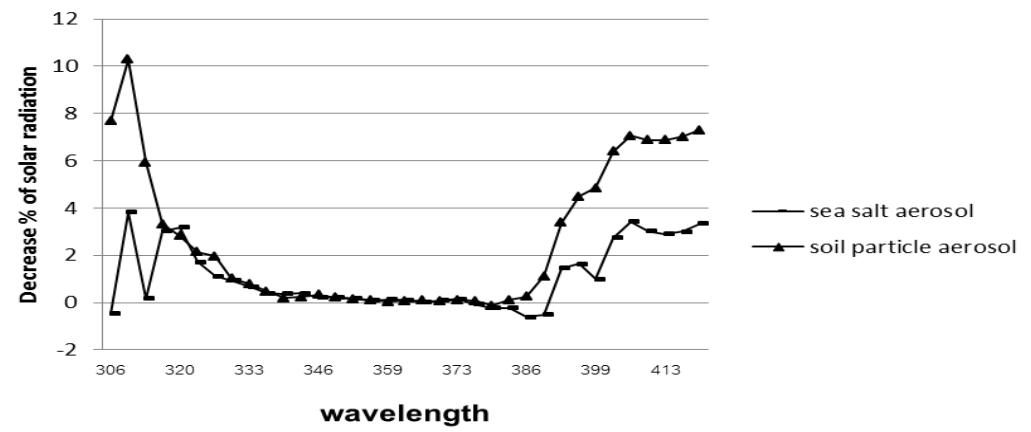

Fig. 6. Decrease in radiation from solar energy and concentration shortwave

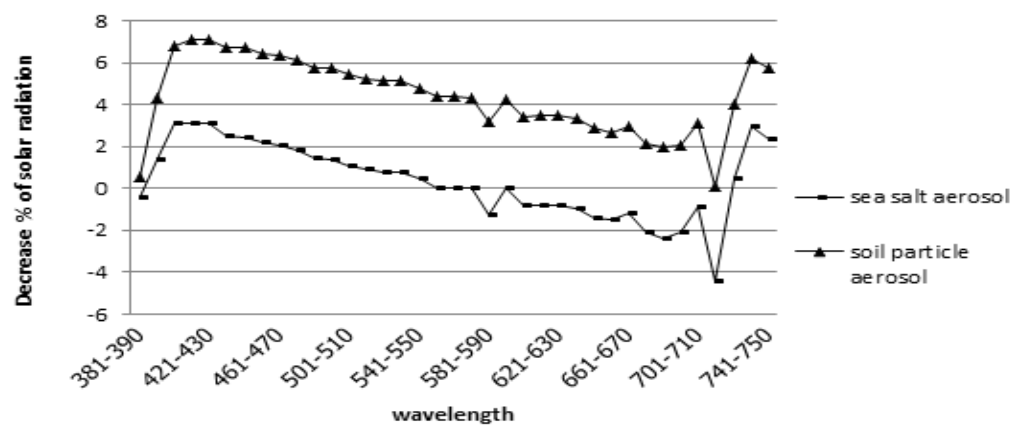

Fig. 7. Decrease in radiation from solar energy and concentration shortwave 306-419

\section{DisCUSSION}

Sea salt aerosols were affected on shortwave energy different from the soil particle. The soil particle showed the inversely relationship to the shortwave spectrum but the sea salt aerosol showed directly and inversely relationship depend on wave length.

Soil particle showed higher decreasing rate than sea salt aerosol at wavelength 306- $330 \mathrm{~nm}$ due to high energy (short wavelength), thus resulting in the scattering of visible light is not a trend (Fig. 6). At wave-length 380-390 nm increase solar radiation $f$ due to the properties of sea salt crystals and at $570-590 \mathrm{~nm}$ and $710-750 \mathrm{~nm}$ showed rapidly reduce energy (Fig. 7).

\section{ACKNOWLEDGEMENT}

The first author would like to express sincere gratitude for The King's Royally Initiated LeamPhakBia Environmental Research and Developmental Project and National Science and Technology Development Agency (NSTDA).Ministry of Science and Technology (MOST).

\section{REFERENCES}

[1] K. Chankaw, "Near surface meteorology," Department of Conservation, Faculty of Forestry, Kasetsart University, Bangkok 1979.

[2] The Air Quality in the Atmosphere, Pollution Control Department to monitor dust in the atmosphere, Air Quality and Noise Management Bureau, Bangkok 2003.

[3] The King's Royally Initiated LeamPhakBia Environmental Research and Developmental Project, Assessment of Solar Energy Balance due to Land Cover Change In Petchaburi Province and Related Areas. 2011.

[4] D. C. Blanchard, "The oceanic production of atmospheric sea salt," $J$ Geophys Res, vol. 90 (Nc1), pp. 961-963, 1985.
[5] J. P. Mulcahy, C. D. O’Dowd, S. G. Jennings, D. Ceburnis, "Significant enhancement of aerosol optical depth in marine air unde high wind conditions," Geophys Res Lett, vol. 35, no. 16, L16810, 2008.

[6] R. Irshad, R. G. Grainger, D. M. Peters, R. A. McPheat, K. M. Smith, G. Thomas, "Laboratory measurements of the optical properties ofsea salt aerosol," Atmos Chem Phys, vol. 9, no. 1, pp. 221-230, 2009.

[7] Y. J. I. K. Kaufman, L. A. Remer, D. Rosenfeld, Y. Rudich, “The effect of smoke, dust and pollution aerosol on shallow cloud developmentover the Atlantic Ocean. Proc Natl," AcadSci, vol. 102, no. 32, pp. 11207-11212, 2005 .

[8] T. Takemura, T. Nakajima, O. Dubovik, B. N. Holben, and S.Kinne, "Single-scattering albedo and radiative forcing ofvarious aerosol species with a global three-dimensional model," J. Climate, vol. 15, pp. 333-352, 2002.

[9] X. Yue and H. Liao, Climatic responses to the shortwave and long-wave direct radiative effects of sea salt aerosol in present day and the last glacia, 2012.

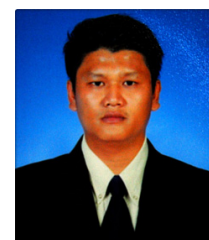

Winai Meesang was born on 5 January1981 in Khon kaen. He is now working in Faculty of Environment, Kasetsart University, 50 Ngam wong wan Rd. Chatuchak, Bangkok, Thailand 10900. He has already got his Ph.D.of Environment Science (Ph.D. Sc.)

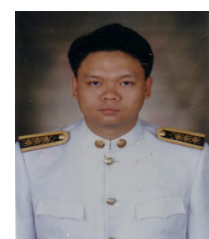

Surat Bualert was born on 8 August 1968 in Bangkok. $\mathrm{He}$ is now working as an assistant professor in dept of Environmental Science, Faculty of Environment, Kasetsart University, 50 Ngam wong wan Rd. Chatuchak, Bangkok, Thailand 10900. He has already got his Ph.D. Air Pollution.

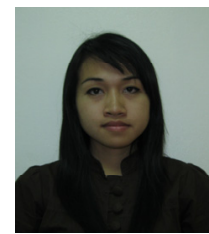

Pantipa Wonglakorn was born on 21 September 1987 in Sisaket. She is now working in Faculty of Environment, Kasetsart University, 50 Ngam wong wan Rd. Chatuchak, Bangkok, Thailand 10900. She got her Bachelor of Environment Science (B. Sc.) 